\title{
debate
}

\section{FUNÇÕES DA SECRETARIA DE ESTADO DA SAÚDE NO SISTEMA ÚNICO DE SAÚdE (SUS) DE SÃO PAULO}

\author{
Evelin Naked de Castro Sá(*) \\ Pedro Dimitrov*
}

\section{RESUMO}

A Constituição da República Federativa do Brasil de 1988 - especialmente quanto ao direito à saúde - e a Legislação complementar ao Sistema Único de Saúde (SUS) determinaram significativa reorganizaçăo jurídico-institucional das funçōes das três esferas de governo na área da saúde. Do ponto de vista organizacional e gerencial, a Secretaria de Estado da Saúde de São Paulo não ofereceu, até o momento, um desenho condizente com as funçōes que deve desempenhar no SUS.

Os autores objetivam caracterizar as dificuldades e as discrepåncias encontradas entre as funçōes que a Secretaria de Estado da Saúde deveria desempenhar no sistema e as que vêm, de fato, realizando.

O trabalho é realizado através da análise de documentos e observaçōes quanto à organização do primeiro nível de subordinação e vinculaçăo à Secretaria, na administraçăo direta e indireta.

Conclui-se pela necessidade da reordenação da Secretaria, com os autores apresentando algumas sugestões, que possam contribuir para cumprir adequadamente suas funções no SUS do Estado de São Paulo.

(*) Departamento de Prática de Saúde Pública/Faculdade de Saúde Pública/Universidade de São Paulo 


\section{CARACTERIZAÇÃO DA COMPETÊNCIA DA SECRETARIA DE ESTADO DASAÚDE (SES) APÓS A CONSTITUIÇÃO DA REPÚBLICA FEDERATIVA DO BRASIL DE 1988 E DA LEGISLAÇÃO COMPLEMENTAR}

Entre os diretrizes políticas consolidadas pela Constituição de 1988, no cenário nacional, estāo os fundamentos de uma radical transformação no sistema de saúde brasileiro. Apoiando-se nas propostas da $8^{\mathrm{a}}$ Conferência Nacional de Saúde realizada em 1986, a Constituição estabeleceu pela primeira vez, de forma relevante, uma seção sobre saúde que trata de três aspectos principais:

- em primeiro lugar, incorpora o conceito mais abrangente de que a saúde tem como fatores determinantes e condicionantes o meio físico, o meio sócio-econômico e cultural, fatores biológicos e a oportunidade de acesso aos serviços que visem à promoção, proteção e recuperação da saúde;

- em segundo lugar, fica legitimado o direito de todos, sem qualquer discriminação, às açōes de saúde em todos os níveis, assim como explicita que o dever de prover o pleno gozo desse direito é responsabilidade do Governo, isto é, do poder público;

- em terceiro lugar, fica estabelecido o Sistema Único de Saúde - SUS, de caráter público, formado por uma rede de serviços regionalizada, hierarquizada e descentralizada, com direção única em cada esfera de governo e sob controle dos seus usuários. Os serviços privados, quando conveniados ou contratados, passam a ser complementares devendo estar subordinados às diretrizes do Sistema Único de Saúde ${ }^{(8,9)}$. 
Considerando este arcabouço constitucional, a legislação complementar estabelece que à direção estadual do Sistema Único de Saúde - SUS compete:

- descentralizar para os municípios os serviços e as ações de saúde;

- gerir as unidades de saúde dos sistemas públicos de alta complexidade, de referência regional ou estadual;

- identificar estabelecimentos hospitalares de referência;

- prestar apoio técnico e financeiro aos Municípios e colaborar com a União na vigilância sanitária de portos, aeroportos e fronteiras;

- estabelecer normas e padrōes, em caráter suplementar, para o controle e avaliação das ações e dos serviços de saúde e de produtos e substâncias de consumo humano;

- coordenar e, em caráter complementar, formular, executar, acompanhar e avaliar ações e serviços de vigilância epidemiológica, vigilância sanitária, alimentação e nutrição, saúde do trabalhador, laboratórios de saúde pública, hemocentros, insumos e equipamentos para saúde;

- participar, junto com órgãos afins, da formulação das políticas e do controle dos agravos ao meio ambiente, da execução das açōes de saneamento básico, dos ambientes e das condições de trabalho;

- acompanhar, avaliar e divulgar os indicadores de morbidade e mortalidade da Unidade Federada ${ }^{(7)}$. 


\section{CARACTERIZAÇÃO DA ESTRUTURA ORGANIZACIONAL ATUAL DA SECRETARIA DE ESTADO DA SAÚDE - SES}

Realizando-se levantamento de documentos legais, até o nível de leis e decretos relativos à estrutura da SES, abrangendo o período de 1954 a 1992, foi possível identificar a organização atual da Secretaria. Modificaçōes estruturais, a nível do Secretário de Estado e de seus subordinados, não foram consideradas, dado que a presente análise abrange apenas a organização da administração superior ${ }^{(4,5,10,11)}$.

A Secretaria de Estado da Saúde apresenta a seguinte estrutura:

\section{A - Administração direta - centralizada:}

1. Gabinete do Secretário;

2. Conselho Técnico Administrativo;

3. Conselho de Atividades de Vigilância;

4. Comissão Interinstitucional de Saúde;

5. Fórum Estadual de Saúde;

6. Comissão de Assuntos de Assistência à Saúde;

7. Fundo Estadual de Saúde - FUNDES;

8. Consultoria Jurídica;

9. Divisão de Documentação;

10. Coordenadoria de Administração Geral; 
11. Coordenadoria de Planejamento Orçamentário e Gestāo;

12. Coordenadoria de Recursos Humanos;

13. Departamento Psiquiátrico II

14. Departamento Médico do Serviço Civil do Estado;

15. Centro de Informações de Saúde;

16. Centro de Vigilância Epidemiológica;

17. Centro de Vigilância Sanitária;

18. Centro de Apoio ao Desenvolvimento da Assistência Integral à Saúde;

19. Centro de Apoio e Assistência Escolar;

20. Centro Técnico de Manutenção de Equipamentos e Edificações;

21. Centro de Referência e Treinamento da AIDS;

22. Centro de Referência de Saúde da Mulher, Nutrição, Alimentação e Desenvolvimento Infantil;

23. Fomento de Educação Sanitária e Imunização em Massa Contra Doenças Transmissíveis - FESIMA

24. Coordenação de Regiōes de Saúde 1;

25. Coordenação de Regiōes de Saúde 2;

26. Coordenação de Regiōes de Saúde 3;

27. Coordenação de Regiōes de Saúde 4;

28. Coordenação de Regiōes de Saúde 5;

29. Coordenação dos Institutos de Pesquisa. 


\section{B - Administração Indireta - Autarquias}

1. Superintendência de Controle de Endemias - SUCEN;

2. Hospital das Clínicas da Faculdade de Medicina da USP - São Paulo;

3. Hospital das Clínicas da Faculdade de Medicina da USP - Ribeirão Preto;

4. Instituto de Assistência Médica dos Servidores Públicos Estaduais.

C - Administração Indireta - FUNDAÇÕES

1. Fundação para o Remédio Popular - FURP;

2. Fundação Oncocentro de São Paulo;

3. Fundação Pró-Sangue Hemocentro de São Paulo.

\section{CARACTERIZAÇÃO DAS FUNÇÕES EXERCIDAS ATUALMENTE PELA SECRETARIA DE ESTADO DA SAÚDE}

Verifica-se que nos últimos anos a Secretaria de Estado da Saúde tem desenvolvido três movimentos básicos: transferência de serviços de saúde para os municípios; incorporação de serviços de saúde da área federal, de outras Secretarias de Estado e da Universidade de São Paulo; e criação de novos órgãos e ampliação dos existentes, para atividades afins e atividades meio no nível central. 


\section{TRANSFERÊNCIA DE SERVIÇOS DE SAÚDE PARA OS MUNICÍPIOS}

Os participantes do Primeiro Seminário dos Níveis Gerenciais do SUDS/SP, realizado em julho de 1988 em Campinas afirmam: "A municipalização total e rápida, em alguns locais, causou o sentimento de imposição. Deixou de ser algo desejável e resultou na elaboração apressada de planos que não resultaram de uma discussão ampla e que não têm consonância com as realidades locais. A avaliação dos planos sobrecarregou os SUDS-R, que não puderam assessorar adequadamente as reformulações e a implantação. Entretanto, alguns grupos consideraram que, pelas circunstâncias, o processo de municipalização não poderia ter se realizado de forma diferente, acreditando que houve um saldo positivo na celebração de 435 convênios" ${ }^{\prime 12}$.

Posteriormente, mais 135 municípios assinaram convênios de municipalização. A utilização do instrumento convênio pela Secretaria não indica, porém, que o tenha feito prioritariamente para a municipalização, pois em 1992 havia 2.933 Convênios das mais diversas naturezas em vigor ${ }^{(2)}$. Deve-se destacar, entretanto, que não ocorreu o processo de municipalização na Capital devido a questōes políticas, administrativas e financeiras.

Neste contexto, ganha fôlego o movimento da Associação das Secretarias e Departamentos Municipais de Saúde do Estado de São Paulo, que representa uma inovação política, traz contribuições importantes e, sobretudo, uma visão crítica do 
processo de municipalização atualmente em curso. A partir das diferentes experiências que vêm vivenciando, assinalam seus membros:

- "a ocorrência da municipalização da assistência primária à saúde e não dos serviços de saúde de maneira geral;

- os órgãos colegiados de decisão nos diferentes níveis, cuja composição é regulada em detalhes pelo SUDS-SP, vêm cumprindo função exclusivamente formal, não tendo sido incorporada a participação dos usuários nas deliberações e sendo afrontada a autonomia municipal;

- o mecanismo de convênio atualmente em vigor coloca os municípios em situação de subordinação dos executivos estadual e federal;

- a política de recursos humanos em vigor constitui-se em importante obstáculo à implementação do sistema, sobretudo em razão da inexistência de isonomia salarial entre servidores de órgãos municipais, estaduais e federais;

- falta de critérios claros para os repasses e reajustes dos recursos feitos pelo Estado, dando margem ao clientelismo político".

Diante desse quadro, o "III Encontro promovido por essa Associação, em Santos, em março de 1989, sistematiza as críticas e propõe novas diretrizes políticas, buscando garantir a autonomia municipal para o planejamento, o gerenciamento administrativo e financeiro da integralidade das ações de saúde, 
incluindo os diversos níveis de complexidade e as ações de saúde coletiva, com a retaguarda dos níveis estadual e federal quando necessária. Nesse sentido, enfatiza a necessidade de democratização das instâncias de decisão e definição de percentuais orçamentários mínimos para a área da saúde (12\% dos orçamentos municipais e, no mínimo, o mesmo montante em níveis estadual e federal); que o total de recursos a serem repassados sejam calculados, não em função de acordos políticos-partidários ou corporativos, mas de critérios técnicos como o perfil epidemiológico, capacidade instalada dos serviços de saúde, a necessidade de expansão das ações de saúde e a existência de serviços de referência regional a nível municipar"(3).

A questão da democratização das instâncias de decisão, do ponto de vista legal, já está equacionada com a Lei Federal $n^{\circ} 8.142$ de 28/12/1990, que estabelece os Conselhos de Saúde para os vários níveis com caráter deliberativo e paritário em relação aos usuários ${ }^{(10)}$.

Quanto à questão dos repasses de recursos, foi regulamentada com a Norma Operacional Básica - SUS 01/93 de 20/05/93 do Ministério da Saúde ${ }^{(6)}$.

É importante destacar que os aspectos legais destas duas questōes, embora já existentes, não são suficientes para equacionar os conflitos emergentes, pois a implantação do SUS é um processo de redistribuição real de poder e de responsabilidade entre as três esferas de governo. 


\section{INCORPORAÇÃO DE SERVIÇOS DE SAÚDE DA ÁREA FEDERAL,DE OUTRAS SECRETARIAS DE ESTADO E DA UNIVERSIDADE DE SÃO PAULO}

A Secretaria de Estado da Saúde incorporou cinco grandes hospitais previdenciários, cem unidades ambulatoriais e cerca de dezesseis mil servidores federais.

A esfera federal após repassar as unidades de saúde foi reduzindo o repasse de recursos financeiros. Assim, ocorreu um sucateamento e até a desativação de cerca de $40 \%$ dos leitos hospitalares. Estes hospitais vivem em sucessivas crises, mesmo porque há conflitos gerenciais em relação aos servidores. Estes conflitos são devidos às diferenças de órgāo empregador de origem, nomenclatura, carreiras, salários e regimes jurídicos de trabalho, além de diferenças ideológicas quanto ao conceito de saúde.

Houve ainda a incorporação, entre outros, do Departamento de Assistência Escolar, do Departamento Médico do Serviço Civil do Estado, do Instituto de Assistência Médica dos Servidores Públicos Estaduais, dos Hospitais das Clínicas Universitários de São Paulo e Ribeirão Preto e da Fundação Pró-Sangue Hemocentro de São Paulo. 


\section{CRIAÇÃO DE NOVOS ÓRGÃOS E AMPLIAÇĀO DOS EXISTENTES PARA} ATIVIDADES AFINS E ATIVIDADES MEIO NO NIVEL CENTRAL

No período mais recente, são criados dois novos Centros que desenvolvem atividades fim: o de Referência e Treinamento da AIDS e o de Referência de Saúde da Mulher, Nutrição, Alimentação e Desenvolvimento Infantil.

As atividades meio são reordenadas a nivel de três Coordenadorias: de Administração Geral, de Planejamento Orçamentário e Gestão e a de Recursos Humanos.

Observa-se, assim, que a Secretaria de Estado da Saúde, ao absorver órgãos da esfera Federal, órgãos da esfera Estadual e ao criar novos órgãos a nível central, transforma-se em uma instituição com uma estrutura central inadministrável, não parecendo ter estabelecido previamente um objetivo; foram sendo criados e/ou/transformados órgãos destinados ao atendimento de problemas emergenciais, aparentemente sem um plano coerente. É, pois, significativo que apresente trinta e seis órgãos e colegiados subordinados ou vinculados diretamente ao Secretário de Estado.

Considerando as competências legais definidas para a unidade federada, no SUS, a organização atual da Secretaria de Estado da Saúde permite identificar duplicidades e multiplicidades, indefinições, dificuldades de coordenação por tipo de 
órgão, regime jurídico, etc - e outros aspectos que tornam clara a urgência de reorganização adequada ao cumprimento daquelas competências. O quadro em anexo mostra a relação entre as competências e a situação organizacional.

Assim, pode-se observar que para uma determinada competência há um grande número de órgãos envolvidos e que não existe possibilidade de instâncias de coordenação entre estes órgãos. Do ponto de vista da Administração, podemos afirmar que a Secretaria Estadual de Saúde, com a atual estrutura, apresenta grande dispersão de esforços e não caminha no sentido da consolidação do SUS.

\section{PROPOSTA DE AJUSTE}

A implantação de uma política pública - no caso o SUS -, implica na compreensão clara de que se trata de um processo.

Assim, considerando o que foi apresentado até o momento e, ainda, que o meio ambiente, o social e o político são extremamente mutáveis, as vinculaçōes necessárias entre a Secretaria Estadual da Saúde com a lógica do Poder da Administração Pública, a configuraçāo interna dos seus recursos e as dificuldades organizacionais, acreditamos que não é possível, nem prudente, estabelecer uma organização estrutural consolidada para a Secretaria, nesta fase de transição. 
Deve-se, isto sim, procurar definir uma organização que reconheça e incorpore um processo permanente de mudanças, com o objetivo de realizar os ajustes da estrutura de acordo com as responsabilidades que o nível estadual vá assumindo na construção do SUS.

Para o atual momento - e apenas para iniciar o debate -, apresenta-se uma proposta de organização inovadora, por grandes áreas e com características de toda a autonomia legal possivel e necessária, traduzidas em figuras jurídicas mais descentralizadas.

Estão juntados órgãos já existentes com outras figuras jurídicas, bem como vinculaçōes que consideramos relevantes, de órgāos de administração indireta.

GRANDES ÁREAS/ÓRGÃOS

\section{POLÍTICAS E MACRO DECISÕES}

- Colegiados maiores:

Conferência Estadual de Saúde

Conselho Estadual de Saúde

Comissāo Bipartide 


\section{EXECUTIVO PRINCIPAL E ADMINISTRAÇÃO SUPERIOR}

- Administração Direta - Centralizada

Secretário de Estado

Gabinete

Gestão financeira de primeira linha - FUNDES

Coordenação para o processo de implantação e acompanhamento do SUS por regiões (órgão temporário)

Coordenação da Administração Indireta

Consultoria e Assessoria Jurídicas

Apoio ao Executivo principal e Administração Superior.

\section{ATIVIDADES FINS E CORRELATAS, COM OUTROS SISTEMAS E SETORES. ÓRGÃOS DE REFERÊNCIAS NO SUS.}

- Administração Indireta - descentralizada

Autarquias

- Hospitais Universitários: USP São Paulo e Ribeirão Preto; UNICAMP Campinas e UNESP - Botucatu

- Instituto de Assistência Médica dos Servidores Públicos Estaduais( ${ }^{\star}$ )

(*) A ser reformulado de acordo com o quadro geral da Administração Pública Paulista. 
Fundações

1) Existentes:

a. Fundação para o Remédio Popular

b. Fundação Oncocentro de São Paulo

c. Fundação Pró-Sangue Hemocentro de São Paulo

2) A serem criadas, por reformulação/reagrupamentos:

a. Fundação para Pesquisa e Apoio à Vigilância a Saúde

b. Fundação de Controle de Endemias

c. Fundação Adolfo Lutz

d. Fundação Instituto Butantã

e. Fundação Pasteur

f. Fundação Dante Pazzanese

g. Fundação Lauro de Souza Lima

h. Fundação Emílio Ribas

\section{REFERÊNCIAS BIBLIOGRÁFICAS}

1. BRASIL. Constituição 1988. Constituicão República Federativa do Brasil. Brasília, Senado Federal, 1988.

2. CASTRO, C.G.J.de; CUNHA, M.L.G.S.; RABELLO, M.C.G.; SÁ, E.N.C. Administraçāo por convênios: um instrumento gerencial de políticas pública II. A Secretaria de Estado da Saúde de São Paulo e a utilizaçăo do instrumento "Convênio" na nova ordem 
constitucional-legal. São Paulo, Faculdade de Saúde Pública/Universidade de São Paulo/Departamento de Prática de Saúde Pública, 1992.

3. CYRINO, A.P.P.; HENRIQUES, C.M.P.; TEIXEIRA, R.R. Perspectivas da Descentralização e Municipalização no Estado de São Paulo. Apresentado no Seminário "Saúde e Planejamento no Brasil". São Paulo, 1989. [Apresentação no Seminário Saúde e Planejamento no Brasil]

4. FUNDAÇĀO DO DESENVOLVIMENTO ADMINISTRATIVO (FUNDAP) Secretaria de Estado da Saúde: concepcão organização e funcionamento. São Paulo, fevereiro, 1987.

5. FUNDAÇĀO DO DESENVOLVIMENTO ADMINISTRATIVO (FUNDAP) Programa Decenal para a área social em São Paulo: gestão pública no setor saúde: um plano estratégico. São Paulo, 1992. (Documentos de Trabalho/Questão Social; 14)

6. MINISTÉRIO DA SAÚDE Portaria $n^{\circ} 545$, de 20 de maio de 1993; estabelece normas e procedimentos reguladores do processo de descentralização da gestão das açōes e senviços de saúde, através da Norma Operacional Básica - SUS, 01/93. D.O.U. de 24/05/93.

7. MINISTÉRIO DA SAÚDE Assessoria de Comunicaçāo Social Lei Orgânica da Saúde Lei $n^{\circ} 8080$, de 19 de setembro de 1990.

8. MINISTÉRIO DA SAÚDE Secretaria Nacional de Assistência à Saúde/SNAS. ABC do SUS - doutrinas e princípios. Brasília, 1990.

9. SECRETARIA DE ESTADO DA SAÚDE Primeira Conferência Estadual de Saúde: saúde uma decisão de todos. São Paulo, 1991.

10. SECRETARIA DE ESTADO DA SAÚDE Leis e decretos de estrutura da SES. São Paulo, 1992.

11. SECRETARIA DE ESTADO DA SAÚDE Organograma. São Paulo, 1993.

12. SECRETARIA DE NIVEIS GERENCIAIS DO SUDS/SP, 10, Campinas, 1988. Belatório final. São Paulo, Secretaria de Estado da Saúde, 1988. 


\section{A NEXO}

\section{RELAÇÃO DAS COMPETÊNCIAS DA DIREÇÃO ESTADUAL DO SUS E OS ÓRGÃOS ATUAIS ENVOLVIDOS}

\begin{tabular}{|c|c|}
\hline $\begin{array}{c}\text { Competências da Direção } \\
\text { Estadual do SUS segundo a } \\
\text { Lel Federal } \mathbf{n}^{\circ} \mathbf{8 0 8 0}\end{array}$ & Órgãos atuais envolvidos \\
\hline \multirow{9}{*}{$\begin{array}{l}\text { - descentralizar para os municípios os } \\
\text { serviços e as ações de Saúde; }\end{array}$} & - Centro de Planejamento Orçamentário e Gestão \\
\hline & - Centro de Vigiláncia Epidemiológica \\
\hline & - Centro de Vigilância Sanitária \\
\hline & - Centro de Apoio e Assisténcia Escolar \\
\hline & - Coordenaçōes de Regiōes de Saúde 1 a 5 \\
\hline & - Superintendéncia de Controle de Endemias \\
\hline & - Coordenaçăo dos Institutos de Pesquisa \\
\hline & - Coordenadoria de Recursos Humanos \\
\hline & - Coordenadoria de Administraçāo Geral \\
\hline \multirow{5}{*}{$\begin{array}{l}\text { - gerir as unidades de saúde dos sistemas } \\
\text { públicos de alta complexidade de } \\
\text { referência Regional e Estadual }\end{array}$} & - Coordenaçōes de Regiōes de Saúde 1 a 5 \\
\hline & - Departamento Psiquiátrico II \\
\hline & - Centro de Referência e Treinamento de AIDS \\
\hline & $\begin{array}{l}\text { - Centro de Referência de Saúde da Mulher, } \\
\text { Nutrição, Alimentação e Desenvolvimento Infantil }\end{array}$ \\
\hline & - Coordenação dos Institutos de Pesquisa \\
\hline \multirow[t]{2}{*}{$\begin{array}{l}\text { - identificar estabelecimentos hospitalares } \\
\text { de referencia }\end{array}$} & $\begin{array}{l}\text { - Centro de Apoio ao Desenvolvimento da } \\
\text { Assistência Integral à Saúde } \\
\end{array}$ \\
\hline & - Coordenaçōes de Regiōes de Saúde 1 a 5 \\
\hline \multirow{8}{*}{$\begin{array}{l}\text { prestar apoio técnico e financeiro aos } \\
\text { Municípios e colaborar com a União na } \\
\text { vigilância sanitária de portos, aeroportos } \\
\text { e fronteiras }\end{array}$} & - Centro de Vigilância Epidemiológica \\
\hline & - Centro de Vigilância Sanitária \\
\hline & $\begin{array}{l}\text { - Centro de Apoio ao Desenvolvimento da } \\
\text { Assistência Integral à Saúde }\end{array}$ \\
\hline & - Centro de Informação à Saúde \\
\hline & - Centro de Planejamento Orçamentário e Gestão \\
\hline & $\begin{array}{l}\text { - Fomento de Educação Sanitária e imunização em } \\
\text { Massa Contra Doenças Transmissíveis }\end{array}$ \\
\hline & - Superintendéncia de Controle de Endemias \\
\hline & - Coordenaçāo dos Institutos de Pesquisa \\
\hline
\end{tabular}




\begin{tabular}{|c|c|}
\hline $\begin{array}{c}\text { Competências da Direção } \\
\text { Estadual do SUS segundo a } \\
\text { Lei Federal } \mathbf{n}^{\circ} \mathbf{8 0 8 0}\end{array}$ & Órgāos atuais envolvidos \\
\hline \multirow{5}{*}{$\begin{array}{l}\text { - estabelecer normas e padrōes, em } \\
\text { caráter suplementar, para o controle } \\
\text { e avaliação das açōes e dos serviços de } \\
\text { saúde e de produtos e substâncias de } \\
\text { consumo humano }\end{array}$} & $\begin{array}{l}\text { - Centro de Apoio ao Desenvolvimento da } \\
\text { Assistência Integral à Saúde }\end{array}$ \\
\hline & - Centro de Vigiláncia Epidemiológica \\
\hline & - Centro de Vigilância Sanitária \\
\hline & - Centro de Informaçóes de Saúde \\
\hline & - Coordenaçáo dos Institutos de Pesquisa \\
\hline \multirow{7}{*}{$\begin{array}{l}\text { coordenar e, em caráter } \\
\text { complementar, formular, executar, } \\
\text { acompanhar e avaliar açōes e serviços } \\
\text { de: vigilância epidemiológica, vigilancia } \\
\text { sanitária, alimentação e nutriçáo, saúde } \\
\text { do trabalhador, laboratórios de saúde } \\
\text { pública, hemocentros, insumos e } \\
\text { equipamentos para saúde }\end{array}$} & - Centro de Vigilância Epidemiológica \\
\hline & - Centro de Vigilância Sanitária \\
\hline & - Coordenaçāo dos Institutos de Pesquisa \\
\hline & $\begin{array}{l}\text { - Centro de Apoio ao Desenvolvimento da } \\
\text { Assistência Integral à Saúde }\end{array}$ \\
\hline & - Fundação Pró-Sangue \\
\hline & - Coordenaçōes de Regiōes de Saúde 1 a 5 \\
\hline & - Fundaçāo para o Remédio Popular \\
\hline \multirow{5}{*}{$\begin{array}{l}\text { participar, junto com órgāos afins, da } \\
\text { formulaçāo das políticas e do controle: } \\
\text { dos agravos ao meio ambiente, da } \\
\text { execuçāo das açóes de saneamento } \\
\text { básico, dos ambientes e das condiçōes } \\
\text { de trabalho }\end{array}$} & - Centro de Vigilância Sanitária \\
\hline & - Coordenação de Regiōes de Saúde 1 a 5 \\
\hline & $\begin{array}{l}\text { - Centro de Apoio ao Desenvolvimento da } \\
\text { Assistência Integral à Saúde } \\
\end{array}$ \\
\hline & - Centro de Vigilância Epidemiológica \\
\hline & - Centro de Informaçóes de Saúde \\
\hline \multirow{3}{*}{$\begin{array}{l}\text { - acompanhar, avaliar e divulgar os } \\
\text { indicadores de morbidade e de } \\
\text { mortalidade da Unidade Federada }\end{array}$} & - Centro de Vigilância Epidemiológica \\
\hline & - Centro de Vigilância Sanitária \\
\hline & - Centro de Informaçōes de Saúde \\
\hline \multirow{3}{*}{$\begin{array}{l}\text { - Conjunto de outras competéncias } \\
\text { exercidas pela SES e que não constam } \\
\text { de forma explícita na Lei Federal } n^{\circ} 8080 \\
\text { como sendo da Direçāo Estadual do } \\
\text { SUS }\end{array}$} & - Departamento Médico do Serviço Civil do Estado \\
\hline & $\begin{array}{l}\text { - Instituto de Assistência Médico dos Servidores } \\
\text { Públicos Estaduais }\end{array}$ \\
\hline & - Coordenação dos Institutos de Pesquisa \\
\hline
\end{tabular}

